\title{
Investigation of Effect of Phytoconstituents Aloe Emodin and Quercetin on Bioavailability of Albendazole
}

\author{
Harsh Verma1, Ravindra Kumar Pandey ${ }^{1, \star}$, Shiv Shankar Shukla², Bina Gidwani², Amber Vyas ${ }^{3}$ \\ ${ }^{1}$ Department of Pharmacognosy, Columbia Institute of Pharmacy Tekari, Raipur, Chhattisgarh, INDIA. \\ ${ }^{2}$ Department of Pharmaceutical Analysis and Quality Assurance, Columbia Institute of Pharmacy Tekari, Chhattisgarh, INDIA. \\ ${ }^{3}$ Department of Pharmaceutics, University Institute of Pharmacy, Pt. Ravishankar Shukla University, Raipur, Chhattisgarh, INDIA.
}

\begin{abstract}
Background/Aim: Albendazole is a drug with benzimidazole nucleus and is poorly absorbed from the gastrointestinal tract due to its low aqueous solubility. The objective of present work was to study the effect of two phytoconstituents aloe emodin and quercetin on the bioavailability of albendazole. Materials and Methods: Estimation was done through UV spectroscopy and HPLC analysis using different concentration of both the phytoconstituents. In-vivo study was conducted to investigate the pharmacokinetics and pharmacodynamic parameters. Results: Results revealed no change in $T_{\max }$ of albendazole and significant changes were observed in $C_{\max }$ values. The $C_{\max }$ was maximum i.e. 0.138 $\mu \mathrm{g} / \mathrm{ml}$ when $20 \mathrm{mg} / \mathrm{kg}$ of quercetin was added as compared to aloe-emodin. The increase in bioavailability of Albendazole was due to the presence of flavonoids in quercetin. The retention time of albendazole as estimated through HPLC chromatogram was found to be 3.2 minutes with acetonitrile and phosphate buffer as the mobile phase. However; albendazole was not detectable in $24 \mathrm{hr}$ plasma sample and values of AUC were found to be zero in all the concentration of aloe emodin and quercetin. Conclusion: Thus, the phytoconstituents rich in flavonoids could be used to increase the bioavailability of poor soluble drugs.
\end{abstract}

Key words: Albendazole, Aloe emodin, Quercetin, Bioavailability, Pharmacokinetics.

\section{INTRODUCTION}

Albendazole (ABZ) is a benzimidazole category drug which is poorly absorbed from the gastrointestinal tract due to its poor aqueous solubility. $\mathrm{ABZ}$ is relatively insoluble in water and other organic solvents; this hinders its absorption behavior in the body. In the mouse and rat, oral absorption of $\mathrm{ABZ}$ is about $20-/ 30 \%$ and in cattle, it is about $50 \%$, compared to about $1-5 \%$ in humans. ${ }^{1}$ Use of herbal products as medicine has increased tremendously now a day's all over the world due to their therapeutic effect and fewer adverse effects as compared to modern medicines. Nature is a good source of medicine about $60 \%$ of anticancer drugs and $75 \%$ of anti-infective drugs approved from 19812002 could be traced to natural origin.
Natural products, as used by the general population, are usually complex mixtures of many compounds. ${ }^{2}$ Both the putative active ingredient(s) and other constituents present in that mixture have the potential to cause interactions with various classes of drugs. Such interactions include induction or inhibition of metabolizing enzymes and drug efflux proteins. It is now claimed and proved that the naturally occurring dietary supplements can modulate hepatic and enterocytic CYP activity. Several flavonoids, which constitute one of the primary classes of active constituents in most herbs, appear to be capable of modulating P-g $\mathrm{P}^{3}$ Co-administration of herbal bioactive constituents with the therapeutic drugs may lead to increased absorption due to
Submission Date: 14-12-2019; Revision Date: 29-05-2020; Accepted Date: 13-08-2020

DOI: 10.5530/ijper.54.4.193 Correspondence: Dr. Ravindra Kumar Pandey Professor, Department of Pharmacognosy, Columbia Institute of Pharmacy Tekari, Raipur-493111, Chhattisgarh, INDIA.

Phone: +919826229321 E-mail: ravindraiop@gmail. com

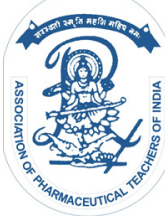

www.ijper.org 
inhibition of P-gp-mediated efflux and CYP-mediated metabolism leading to potential toxic effects. ${ }^{4}$ The structure of albendazole, aloe emodin and quercetin are shown in Figure $1(\mathrm{a}, \mathrm{b}, \mathrm{c})$. The objective of the present work was to evaluate the effect of two phytoconstituents (Aloe emodin and Quercetin) on the bioavailability of albendazole in rabbits.

Aloe emodin is an anthrone derivative which exists in aloe. It is present in low levels in plants and it is thought to arise through oxidative decomposition of its glycosides rather than through direct biosynthesis. Aloe emodin is a botanical products used for its cathartic activity and is used in traditional medicine and in retail products, such as over-the-counter drugs, dietary supplements and cosmetics. ${ }^{5}$ It possesses wide pharmacological actions like Anti-cancer property, Anti-viral properties, Xanthine oxidase inhibitors, Antibacterial properties etc.

Quercetin, a member of the flavonoids family, is one of the most prominent dietary antioxidants. It is ubiquitously present in foods, including vegetables, fruit, tea and wine as well as countless food supplements and is claimed to exert beneficial health effects. ${ }^{6,7}$ It possesses hepatoprotective properties, anti-cancer properties, neuroprotective activity and anti-oxidant properties.

Extensive literature reports work done on these two phytoconstituents. Kesarwani and Gupta et al. in the year 2013 summarized various available novel drug delivery technologies of herbal drugs to achieve the better therapeutic response. The authors have compiled the profile of most of the natural bioenhancer with their mechanism of action and studies on enhancement in drug bioavailability exhibited by these natural compounds. ${ }^{6}$ Early in the year 2008; Umathe et al. established the inhibitory influence of quercetin (2, 10 and $20 \mathrm{mg} / \mathrm{kg}$, p.o.) on CYP3A activity by an in vivo method of estimating levels of Midazolam in female rats pre-treated with Dexamethasone. ${ }^{7}$ Quercetin pretreatment increased $\mathrm{AUC}_{0-1}$ of Pioglitazone after oral administration by $75 \%$ and $\mathrm{AUC}_{0-1}$ after intravenous administration by $25 \%$ suggesting decreased metabolism, which could be due to inhibition of CYP3A by Quercetin. In 2006; Shin et al. investigated the effect of Quercetin, a dual inhibitor of CYP3A4 and P-gp, on the bioavailability and pharmacokinetics of Tamoxifen and one of its metabolites, 4-hydroxy Tamoxifen, in rats. The current study showed that co-administration of Quercetin $(2.5$ and $7.5 \mathrm{mg} / \mathrm{kg})$ significantly $(\phi<0.05)$ increased the absorption rate constant $(\mathrm{Ka})$, peak concentration $\left(\mathrm{C}_{\max }\right)$ and the areas under the plasma concentration-time curve (AUC) of Tamoxifen. The absolute bioavailability (AB \%) of
Tamoxifen with 2.5 and $7.5 \mathrm{mg} / \mathrm{kg}$ Quercetin ranged from $18.0 \%$ to $24.1 \%$, which was significantly higher than the control group, $15.0 \%(p<0.05) .^{8}$

Similarly, in the year 2005; Vinson et al. reported the effect of Aloe on the human absorption of Vitamins $\mathrm{C}$ and $\mathrm{E}$, the most popular Vitamin supplements. The plasma bioavailability of vitamins $\mathrm{C}$ and $\mathrm{E}$ were determined in normal fasting subjects, with eight subjects for Vitamin C and ten subjects for Vitamin E. Results indicated that the Aloes improved the absorption of both Vitamins C and E. 'The absorption is slower and the Vitamins last longer in the plasma with the Aloes. Aloe is the only known supplement to increase the absorption of both of these vitamins and should be considered as a complement to them. In 2002; Nagy et al. studied metabolic breakdown of Albendazole by mucosal CYP3A4 enzyme co-administered Albendazole $(10 \mathrm{mg} / \mathrm{kg})$ with grapefruit juice. ${ }^{10}$ Concentrations of Albendazole sulfoxide (ABZSX), the active metabolite of Albendazole, were compared with those after Albendazole administered with water, a fatty meal, or grapefruit juice plus Cimetidine $(10 \mathrm{mg} / \mathrm{kg}$ ). In comparison to water, maximum ABZSX concentration $\left(\mathrm{C}_{\max }\right)$ enhanced 6.5-fold by a fatty meal and 3.2-fold by grapefruit juice. ${ }^{11}$ Recently in the year 2012; Dudhatra reviewed on herbal bio enhancer and give emphasis on novel active principles from a vast array of unexploited plants having a role as a bioavailability and a bio efficacy enhancer. In this review, recent advancement in bioavailability enhancement of drugs by compounds of herbal origin was described. ${ }^{12}$ Herbal bio enhancers have been shown to enhance bioavailability and bio efficacy of different classes of drugs, such as antibiotics, ant tuberculosis, antiviral, antifungal and anticancerous drugs at low doses. They have also improved oral absorption of nutraceuticals like vitamins, minerals, amino acids and certain herbal compounds. ${ }^{13}$ Their

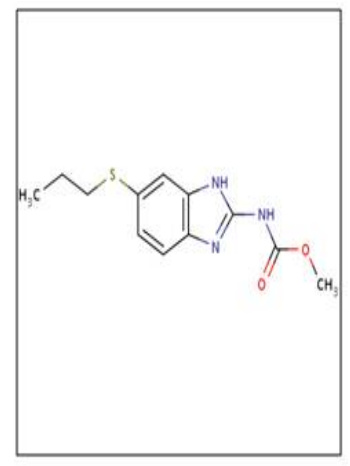

(a)

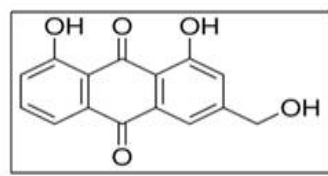

(b)

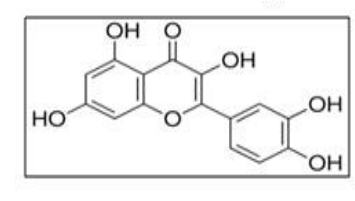

(c)
Figure 1: (a) structure of Albendazole (b) structure of aloe emodin and (c) quercetin. 
mechanism of action is mainly through absorption process, drug metabolism and action on drug target was described. Keeping in mind; all these aspects, we aimed to enhance the bioavailability of albendazole using natural bio enhancer (aloe emodin and quercetin). The pharmacokinetics and pharmacodynamics parameters were estimated by HPLC analysis.

\section{MATERIALS AND METHODS}

Pure drug Albendazole was purchased from Pramukh Pharmaceutical Pvt. Ltd. (Gujarat, India), whereas the phytoconstituents (Quercetin and Aloe emodin) were purchased from Yucca Enterprises, Mumbai, Maharashtra. The chemicals and solvents (DMSO, methanol, acetonitrile etc) were purchased from Merck, Mumbai. All the chemicals used in the study were of analytical grade.

\section{Experimental work Analysis of drug}

For the identification and estimation of purity; HPLC analysis of all the 3 pure drugs (Albendazole, Quercetin, Aloe emodin) was performed in the Instrument laboratory of Columbia Institute of Pharmacy, Raipur. For this; the drugs were individually dissolved in DMSO and solution of concentration $10 \mathrm{ppm}$ for each drug was prepared. The chromatographic condition was set at flow rate of $1.0 \mathrm{ml} / \mathrm{min}$ using different solvent system (HPLC, YoungLin, Korea). The chromatographic conditions of HPLC analysis of drugs are described in Table 1.

\section{Ultraviolet spectroscopy (UV spectroscopy)}

UV spectroscopy (UV-Visible Spectrometer, Double beam, Shimadzu UV 1800, Japan) was done for the determination of maximum absorbance $\left(\lambda_{\max }\right)$ and compared with the standard monograph. This was done by preparing appropriate dilution of drug using DMSO as the solvent. $10 \mu \mathrm{g} / \mathrm{ml}$ of Albendazole solution was scanned separately in the range of $200-800 \mathrm{~nm}$ to determine the wavelength of maximum absorption. .

\section{Fourier Transform Infrared spectroscopy}

FTIR spectroscopy was performed by $\mathrm{KBr}$ press, pellet method. For this, $10 \mathrm{mg}$ of drug sample and $400 \mathrm{mg}$ of $\mathrm{KBr}$ (Potassium bromide) was taken in a mortar and triturated with pestle. A small amount of the triturated sample was taken and kept onto the sample holder and scanned from $4000 \mathrm{~cm}^{-1}$ to $400 \mathrm{~cm}^{-1}$ in F.T.I.R. Spectrophotometer (Shimadzu FTIR Affinity
8400S, Japan. The spectra obtained was recorded and interpreted for the functional group peaks.

\section{Melting point}

The melting point of Albendazole was determined by using melting point apparatus. For this, a small amount of drug sample was filled in capillary tube which was one sided closed and placed in a melting point apparatus and the temperature at which drug melts was noted.

\section{Preparation of calibration curve with DMSO}

An accurately weighted amount of Albendazole equivalent to $100 \mathrm{mg}$ was dissolved in small amount of DMSO in $100 \mathrm{ml}$ volumetric flask and volume made up to $100 \mathrm{ml}$ with the DMSO. From this stock solution, $5 \mathrm{ml}, 10 \mathrm{ml}, 15 \mathrm{ml}, 20 \mathrm{ml}$ and $25 \mathrm{ml}$ were withdrawn and diluted up to $10 \mathrm{ml}$ with the pure DMSO in $10 \mathrm{ml}$ volumetric flask to get concentration of $5 \mu \mathrm{g}$, $10 \mu \mathrm{g}, 15 \mu \mathrm{g}, 20 \mu \mathrm{g}$ and $25 \mu \mathrm{g}$ respectively. Diluted solutions of different concentration were injected to HPLC and area under curve was obtained. For the preparation of standard curve mobile phase was Acetonitrile: Phosphate buffer (70:30) and flow rate was $1 \mathrm{ml} / \mathrm{min}$.

\section{Pharmacokinetic study}

Bioavailability is one of the essential tools in pharmacokinetics, as it must be considered when calculating dosages for non-intravenous routes of administration. Bioavailability studies are of two types Single dose bioavailability studies: - Single dose bioavailability studies are very common, easy, offer less exposure and less tedious. But, it's difficult to predict the steady state characteristics and inter subject variability by this method.

Multiple dose study bioavailability studies: Multiple dose study is difficult to control (poor subject compliance), exposes the subject to more drug, highly tedious and time consuming ${ }^{14}$

In pharmacokinetic study, the parameters $\mathrm{C}_{\max }, \mathrm{T}_{\max }$, AUC were estimated through plasma/blood profile.

\section{Pharmacodynamics study}

For this study, New Zealand white rabbit 1500-2000g of either sex were procured from the Animal House of Department of Pharmacology, Columbia Institute of Pharmacy, Raipur. The animals were acclimatized for one week under laboratory conditions. They were housed in polypropylene cages and maintained at $27^{\circ} \mathrm{C}$ $\pm 2^{\circ} \mathrm{C}$ under $12 \mathrm{hrs}$ dark / light. They were fed with standard rabbit feed and water ad libitum was provided. The litter in the cages was renewed thrice a week to ensure hygeinity and maximum comfort for animals. 
The study was approved by Animal Ethical Committee (Ethical clearance number CIP/IAEC/2013-14/038).

\section{Dose calculation for animal (Rabbit)}

The adult dose of Albendazole for humans is OD and depends upon disease condition. For rabbit the dose was calculated by multiplying the adult human dose with conversion factor 0.07 to produce dose for rabbit. It was found $28 \mathrm{mg} / \mathrm{kg}$ body weight for $1.5 \mathrm{~kg}$ weight rabbit. On the basis of this; the dose for each animal was calculated according to their body weight. The animals were divided into five groups.

Group I: Albendazole (28mg/kg body weight) alone administration

Group II: Albendazole (28mg/ $\mathrm{kg}$ body weight) pretreated with Aloe emodin (10 $\mathrm{mg} / \mathrm{kg}$ bodyweight) half hour before Albendazole administration

Group III: Albendazole ( $28 \mathrm{mg} / \mathrm{kg}$ body weight) pretreated with Aloe emodin $(20 \mathrm{mg} / \mathrm{kg}$ bodyweight) half hour before Albendazole administration

Group IV: Albendazole ( $28 \mathrm{mg} / \mathrm{kg}$ body weight) pretreated with Quercetin (10mg/kg bodyweight) half hour before Albendazole administration

Group V: Albendazole ( $28 \mathrm{mg} / \mathrm{kg}$ body weight) pretreated with Quercetin $(20 \mathrm{mg} / \mathrm{kg}$ bodyweight) half hour before Albendazole administration.

\section{Drug administration in animal}

Animals were kept in the rabbit cage gently. Xylocaine jelly applied to the infant oral feeding tube and inserted smoothly in the rabbit mouth up to $3 / 4$ of total length of the tube so that it reaches to the stomach. Drug suspension was filled in a $5 \mathrm{ml}$ syringe and injected through the oral feeding tube into the mouth of a rabbit.

\section{Collection of blood sample}

Blood samples were collected from the marginal ear vein of rabbit in different time interval 1, 2, 3, 4, 5, 6, 7 $\mathrm{hr}$ and $24 \mathrm{hr}$ through $1.0 \mathrm{ml}$ of an insulin syringe. $1.0 \mathrm{ml}$ of blood was collected and stored in a pre-heparinized tube of $1.5 \mathrm{ml}$ capacity.

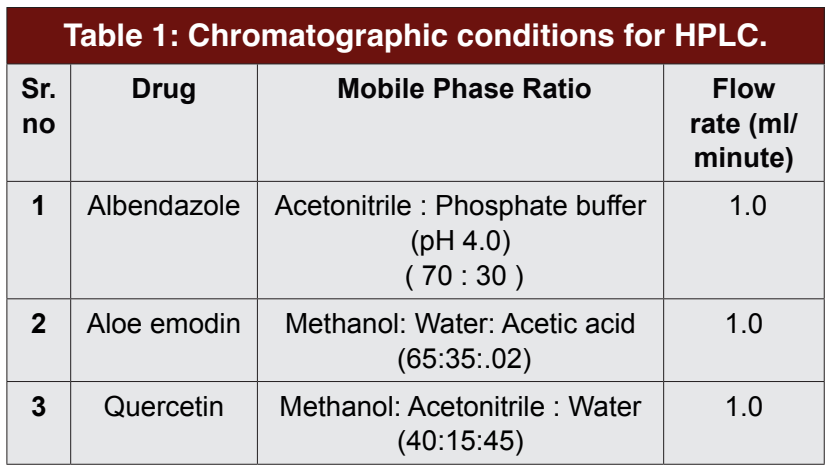

\section{Separation of plasma from blood}

After collection of blood samples immediately separation of plasma was done by micro centrifuge. Blood samples were centrifuged at 13000 RPM for $10 \mathrm{~min}$. After centrifugation, plasma was separated as supernatant and stored in a different tube in $-20^{\circ} \mathrm{C}$ in a frozen state in a deep freezer until analysis.

\section{Extraction of Albendazole from plasma}

Extraction of Albendazole was done by the method reported by Gracia et al. In order to precipitate proteins, two $\mathrm{ml}$ of methanol was added to each aliquot (0.4 $\mathrm{ml}$ ) of plasma sample. After vortex-mixing for 1 min, samples were centrifuged at $3000 \mathrm{~g}$ for $10 \mathrm{~min}$ and filtered through PVDF Durapore $0.45 \mathrm{~mm}$ filter (Millipore). In order to quantify ABZ concentration, 30 $\mathrm{ml}$ of the filtered aliquot-fractions were injected into the HPLC system.

\section{HPLC analysis of plasma}

After extraction of Albendazole from plasma, filtrate obtained by extraction was injected to the HPLC system for the determination of the concentration, of Albendazole in a sample of the different time interval. Mobile phase was Acetonitrile: phosphate buffer (70:30) and flow rate was $1.0 \mathrm{ml} / \mathrm{min}$. Samples were analyzed at $308 \mathrm{~nm}$ and under these conditions, retention time was $4.0 \mathrm{~min}$.

\section{RESULTS AND DISCUSSION}

\section{UV- Visible spectroscopy of pure drug (Lambda max determination)}

The absorption maxima $\left(\lambda_{\max }\right)$ of drugs were determined by Systronic 2202 PC based UV visible double spectrophotometer. The results were within the standard range and are shown in Table 2 . The results obtained confirmed that the samples were Albendazole, quercetin and aloe-emodin. These results were compatible with that of the pharmacopeia.

\section{Analysis of pure drug by HPLC}

On the basis of lambda max obtained by UV spectroscopy, identification of pure drugs was done by

\begin{tabular}{|c|c|c|c|}
\hline \multicolumn{4}{|c|}{ Table 2: $\boldsymbol{\lambda}_{\max }$ of drugs. } \\
\hline $\begin{array}{c}\text { Sr. } \\
\text { No }\end{array}$ & Drug & $\begin{array}{c}\lambda_{\max } \text { obtained (in } \\
\text { nm) }\end{array}$ & $\begin{array}{c}\text { Standard } \\
\text { value (in } \mathbf{n m} \text { ) }\end{array}$ \\
\hline $\mathbf{1}$ & Albendazole & 308 & 309 \\
\hline $\mathbf{2}$ & Quercetin & 368 & 372 \\
\hline $\mathbf{3}$ & Aloe emodin & 410 & 254,410 \\
\hline
\end{tabular}


HPLC and retention times are shown in Table 3. The HPLC chromatograms of albendazole, aloe emodin and quercetin are shown in Figure 2 (a), (b) and (c).

\section{FTIR spectroscopy}

The FTIR spectrum of albendazole showed the characteristic absorption of various functional groups at $3327.21 \mathrm{~N}-\mathrm{H}$ stretch (secondary amine), 2956.87 C-H stretch Alkane, 1674.21 C=N stretch, Nitrile group, $1317.38 \mathrm{C}-\mathrm{O}-\mathrm{C}$ stretch, Aromatic group. The characteristic absorption peaks of Albendazole, aloe emodin and quercetin are discussed in Table 4.

The FTIR spectrum of Aloe emodin showed the absorption peaks at 3429. OH, (Alcohol), 3294.42, =C-H, (Alkene and Aromatic), $1672.28 \mathrm{C}=\mathrm{O},($ Carbonyl), 1429.25 C-C stretch (in-ring). The FTIR spectrum of quercetin showed the characteristic absorption of various functional groups at 3564.45. OH, (Alcohol, Phenol), 1674.21, C=C, (Alkene), 869.98 C-H Aromatic, 754.17 Ar-H, Ortho substituted aromatic. The FTIR spectra of Albendazole, aloe-emodin and quercetin are shown in Figure 3 (a), (b) and (c).

\begin{tabular}{|c|c|c|}
\hline \multicolumn{3}{|c|}{ Table 3: Retention time of pure drug. } \\
\hline Sr. no & Drug & $\begin{array}{c}\text { Retention time } \\
\text { (minutes) }\end{array}$ \\
\hline 1 & Albendazole & 3.21 \\
\hline 2 & Aloe emodin & 3.55 \\
\hline 3 & Quercetin & 6.71 \\
\hline
\end{tabular}

Table 4: FTIR Spectra of Albendazole, aloe -emodin and quercetin.

\begin{tabular}{|c|c|}
\hline Wave Number(cm-1) & Characteristic Absorption \\
\hline \multicolumn{2}{|c|}{ Albendazole } \\
\hline 3327.21 & N-H stretch, secondary amine \\
\hline 2956.87 & C-H stretch, Alkane \\
\hline 1712 & C=N stretch, Nitrile group \\
\hline 1317.38 & C-O stretch, Aromatic group \\
\hline 3429.43 & Aloe emodin \\
\hline 3294.42 & OH, Alcohol \\
\hline 1672.28 & C-H, Alkene and Aromatic \\
\hline 1429.25 & C-C stretch (in-ring) \\
\hline 3564.45 & Quercetin \\
\hline 1674.21 & OH, Alcohol, Phenol \\
\hline 869.98 & C=C, Alkene \\
\hline 754.17 & Ar-H, Ortho substituted \\
& aromatic \\
\hline \multicolumn{2}{|c|}{} \\
\hline
\end{tabular}

\section{Melting point}

The melting point of Albendazole was found to be $209^{\circ} \mathrm{C}$. It was as per the pharmacopeia.

\section{Preparation of standard curve by HPLC}

Standard calibration curve in Table 5 shows the area under the curve of albendazole at different concentration range of 5, 10, 15, 20 and $25 \mu \mathrm{g} / \mathrm{ml}$ in DMSO. Figure 4 shows the standard curve of Albendazole, which was found to be linear in the range of $5-25 \mu \mathrm{g} / \mathrm{ml}$ at 308 $\mathrm{nm}$. The regression value was found to be 0.9974 .

\section{Pharmacokinetic and Pharmacodynamics study}

Experimental and control group plasma samples were analyzed for Albendazole concentration in HPLC system and results were reported as area under the curve. Albendazole was not detectable in $24 \mathrm{hr}$ plasma sample and value of AUC were found zero in every animal in each group. The result obtained from analysis of pure drugs and different groups animals at different time are shown in Table 5 and 6. From the table it is clear that at the end of $24 \mathrm{hr}$, the AUC value was found to be zero in all the groups which indicates that Albendazole was not present in the sample. The AUC values were maximum when $20 \mathrm{mg} / \mathrm{kg}$ of quercetin was added in the sample. The amount of aloe emodin led to
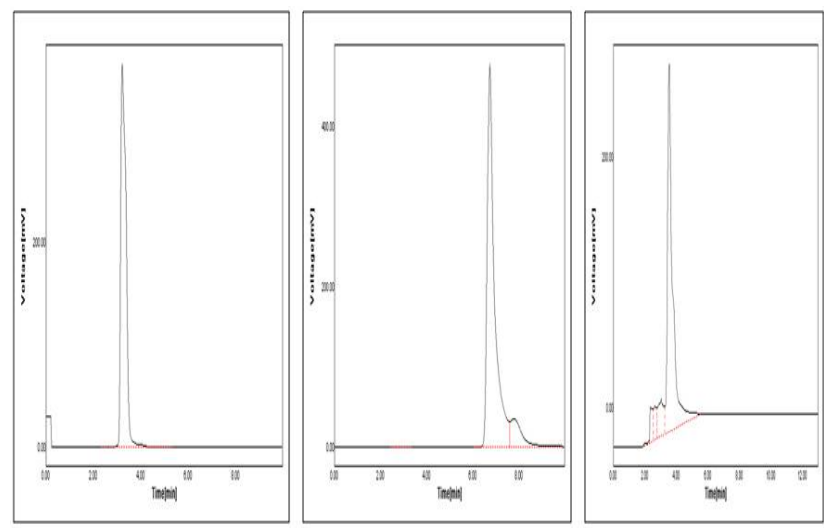

Figure 2: (a) HPLC chromatogram of (a) Albendazole (b) Quercetin and (c) Aloe emodin.

\begin{tabular}{|c|c|c|}
\hline \multicolumn{3}{|c|}{ Table 5: Area under curve value of standard } \\
solutions. \\
\hline Sr. No & $\begin{array}{c}\text { Concentration (in } \\
\boldsymbol{\mu g} / \mathrm{ml} \text { ) }\end{array}$ & Area under curve \\
\hline $\mathbf{1}$ & $\mathbf{5}$ & 1475.788 \\
\hline $\mathbf{2}$ & 10 & 2987.126 \\
\hline $\mathbf{3}$ & 15 & 4220.935 \\
\hline $\mathbf{4}$ & 20 & 6020.124 \\
\hline $\mathbf{5}$ & 25 & 7370.869 \\
\hline
\end{tabular}




\begin{tabular}{|c|c|c|c|c|c|}
\hline $\begin{array}{c}\text { Time } \\
\text { (in Hour) }\end{array}$ & $\begin{array}{c}\text { AUC of Albendazole } \\
\text { (28mg/kg) Control } \\
\text { group }\end{array}$ & $\begin{array}{c}\text { AUC of Albendazole } \\
(28 \mathrm{mg} / \mathrm{kg})+ \\
\text { Quercetin }(10 \mathrm{mg} / \\
\mathrm{kg})\end{array}$ & $\begin{array}{c}\text { AUC of Albendazole } \\
(28 \mathrm{mg} / \mathrm{kg})+ \\
\text { Quercetin }(20 \mathrm{mg} / \\
\mathrm{kg})\end{array}$ & $\begin{array}{c}\text { AUC of Albendazole } \\
(28 \mathrm{mg} / \mathrm{kg})+\text { Aloe } \\
\text { emodin }(10 \mathrm{mg} / \mathrm{kg})\end{array}$ & $\begin{array}{c}\text { AUC of Albendazole } \\
(28 \mathrm{mg} / \mathrm{kg})+\text { Aloe } \\
\text { emodin }(20 \mathrm{mg} / \mathrm{kg})\end{array}$ \\
\hline 1 & 9.5396 & $18.00 \pm 1.45$ & $25.99 \pm 2.63$ & $9.79 \pm 2.29$ & $9.59 \pm 2.13$ \\
\hline 2 & 12.18258 & $22.43 \pm 2.34$ & $30.80 \pm 3.11$ & $12.44 \pm 2.98$ & $12.16 \pm 2.97$ \\
\hline 3 & 15.43122 & $27.45 \pm 2.23$ & $38.22 \pm 2.65$ & $13.67 \pm 1.98$ & $13.77 \pm 1.69$ \\
\hline 4 & 14.8515 & $25.01 \pm 3.70$ & $35.21 \pm 4.50$ & $13.15 \pm 2.92$ & $13.86 \pm 3.50$ \\
\hline 5 & 12.01226 & $23.98 \pm 4.89$ & $29.28 \pm 6.61$ & $8.35 \pm 2.20$ & $9.49 \pm 2.67$ \\
\hline 6 & 8.48684 & $17.63 \pm 5.60$ & $23.16 \pm 5.72$ & $5.37 \pm 3.21$ & $7.07 \pm 1.88$ \\
\hline 7 & 1.51934 & $12.66 \pm 4.70$ & $18.05 \pm 4.67$ & $2.11 \pm 2.88$ & $3.19 \pm 2.92$ \\
\hline 24 & 0 & $0 \pm 0$ & $0 \pm 0$ & $0 \pm 0$ & $0 \pm 0$ \\
\hline
\end{tabular}

\begin{tabular}{|c|c|c|c|c|c|}
\hline $\begin{array}{l}\text { Pharmaco-kinetic } \\
\text { parameter }\end{array}$ & $\begin{array}{c}\text { Albendazole alone } \\
\text { group } \\
(28 \mathrm{mg} / \mathrm{kg})\end{array}$ & $\begin{array}{c}\text { Albendazole + } \\
\text { Quercetin } \\
(10 \mathrm{mg} / \mathrm{kg})\end{array}$ & $\begin{array}{c}\text { Albendazole } \\
+ \text { quercetin } \\
(20 \mathrm{mg} / \mathrm{kg})\end{array}$ & $\begin{array}{c}\text { Albendazole + Aloe } \\
\text { Emodin } \\
(10 \mathrm{mg} / \mathrm{kg})\end{array}$ & $\begin{array}{c}\text { Albendazole + Aloe } \\
\text { emodin } \\
(20 \mathrm{mg} / \mathrm{kg})\end{array}$ \\
\hline $\mathrm{AUC}_{0-24}(\mu \mathrm{g} / \mathrm{ml}$.hour $)$ & 9.252 & 18.395 & 25.090 & 8.10949 & 8.641 \\
\hline $\mathrm{T}_{\max }$ & $3 \mathrm{hr}$ & $3 \mathrm{hr}$ & $3 \mathrm{hr}$ & $3 \mathrm{hr}$ & $3 \mathrm{hr}$ \\
\hline $\mathrm{C}_{\max }(\mu \mathrm{g} / \mathrm{ml})$ & 0.03254 & 0.04086 & 0.13788 & 0.0319 & 0.03164 \\
\hline
\end{tabular}

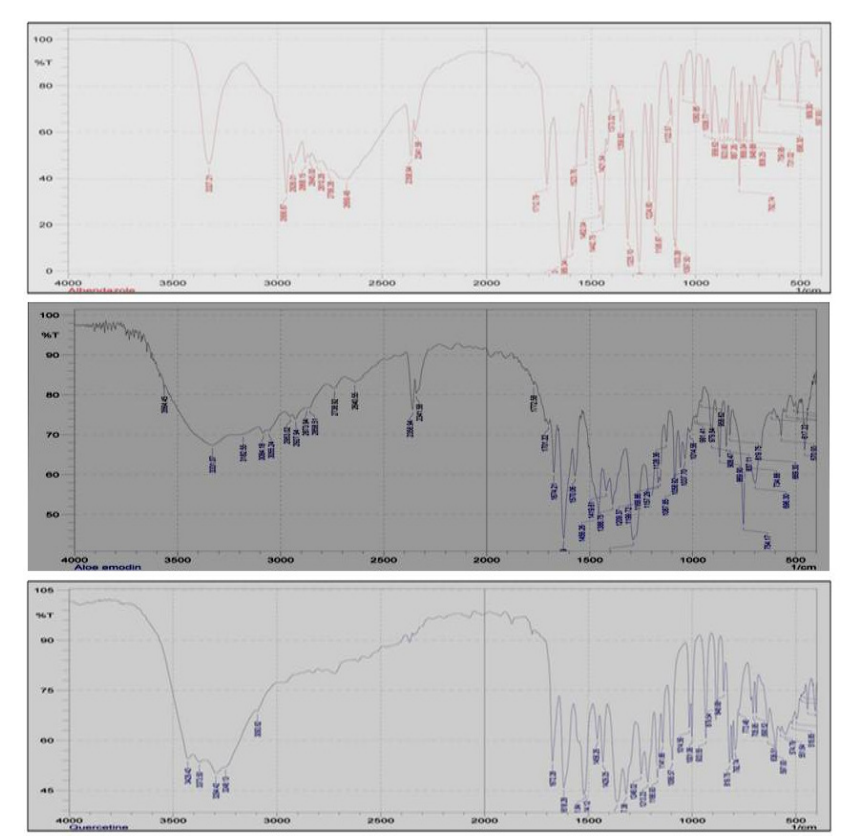

Figure 3: FTIR spectra of (a) Albendazole, (b) Aloe emodin and (c) Quercetin.

no significant changes in AUC at both the doses of 10 $\mathrm{mg} / \mathrm{kg}$ and $20 \mathrm{mg} / \mathrm{kg}$.

\section{Pharmacokinetic parameters of Albendazole}

On the basis of above observations different pharmacokinetic parameters of experimental and control groups were calculated and results were as follows. The mean plasma albendazole concentration vs

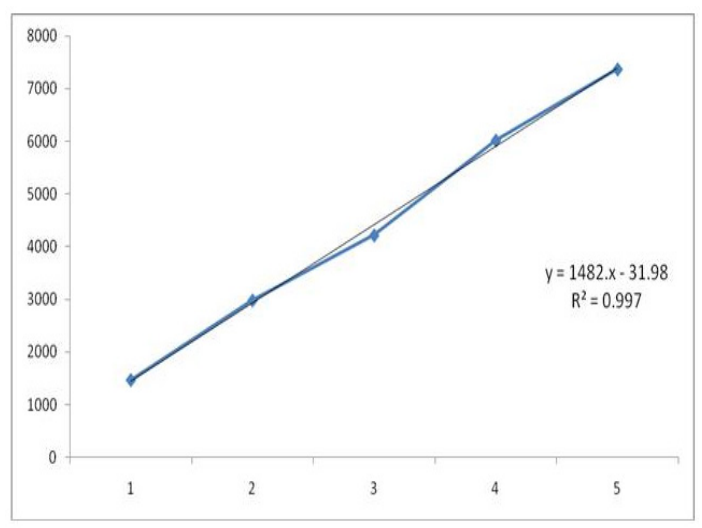

Figure 4: Standard curve of Albendazole by HPLC.

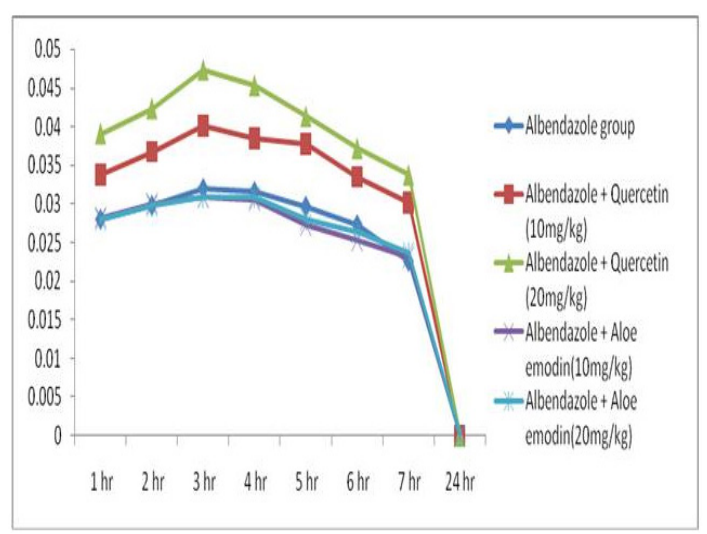

Figure 5: Mean plasma Albendazole concentration - time curve in different groups. 
time curve in different groups is shown in Figure 5. On the basis of the results obtained; (enlisted in Table 7) the pharmacokinetic parameters and activity of Albendazole was greatly influenced by the physicochemical properties and metabolic pathways of the active molecules. The anthelmintics are only sparingly soluble in water and their absorption and pharmacokinetics are affected by their aqueous solubility.

\section{CONCLUSION}

The bioavailability of albendazole pretreated with quercetin $(10 \mathrm{mg} / \mathrm{kg}$ and $20 \mathrm{mg} / \mathrm{kg})$ was increased $(p<0.05)$ significantly compared with the control (Albendazole $28 \mathrm{mg} / \mathrm{kg}$ ). Pretreatment with aloe emodin $(10 \mathrm{mg} / \mathrm{kg}$ and $20 \mathrm{mg} / \mathrm{kg}$ ) led to no increase in bioavailability of albendazole. Previous studies reported that aloe emodin is an inhibitor of cytochrome enzymes in vitro but in the present study it was found there is no inhibitory effect on this enzyme system in vivo. Pretreatment with quercetin increases the bioavailability of albendazole significantly by the inhibition of cytochrome $\mathrm{Cyp}_{3} \mathrm{a}_{4}$ enzyme, which is mainly responsible for the metabolism of albendazole system and hence increases the bioavailability of albendazole.

\section{ACKNOWLEDGEMENT}

The authors are grateful to the Department of Science and Technology (DST-FIST) Letter no-SR/FST/ COLLEGE/2018/418, New Delhi for providing funding for the research laboratories of Department of Pharmacognosy, Department of Pharmaceutical Analysis and Quality Assurance, Columbia Institute of Pharmacy, Raipur (C.G.)

\section{CONFLICT OF INTEREST}

The authors declare no conflict of interest.

\section{ABBREVIATIONS}

UV: Ultra-violet spectroscopy; HPLC: High Performance Liquid Chromatography; $\mathbf{C}_{\text {max }}$ : maximum concentration; $\mathbf{t}_{\max }:$ maximum time; AUC: Area under Curve; ABZ: Albendazole; CYP: Cytochrome P; P-gp: P-glycoprotein; CYP3A: Cytochrome P450 3A; Ka: Absorption kinetics; AB: Absolute Bioavailability; p.o: Per os means by mouth; ABZSX: Albendazole sulfoxide; DMSO: Dimethyl Sulphoxide; KBr: Potassium Bromide; FTIR: Fourier Transform Infra-red spectroscopy; OD: Once daily; SD: Standard deviation; ANOVA: Analysis of Variance.

\section{REFERENCES}

1. Dayan AD. Albendazole, mebendazole and praziquantel. Review of nonclinical toxicity and pharmacokinetics. Acta Tropica. 2003;86:141-59.

2. Gupta R, Gabrielsen B, Ferguson SM. Nature medicines: traditional knowledge and Intellectual property management case studies from $\mathrm{NIH}$ USA. Current Drug Discovery Technologies. 2009;2(4):203-19.

3. Manach C, Scalbert A, Marand C. Polyphenol: Food source and bioavailability. American Journal of Clinical Nutrition. 2004;79(5):727-47.

4. Hetal T, Bindesh P, Thakkar S. A review on techniques for oral bioavailability enhancement of drugs. International Journal of Pharmaceutical Sciences Review and Research. 2010;4(3):203-23.

5. Umathe SN, Dixit PV, Kumar V, Bansod KU, Wanjari MM. Quercetin pretreatment increases the bioavailability of pioglitazone in rats: involvement of CYP3A inhibition. Biochemical Pharmacology. 2008;75(8):1670-6.

6. Gupta KK. Bioavailability enhancers of herbal origin: An overview. Asian Pacific Journal of Tropical Biomedicine. 2013;3(4):253-66.

7. Kai M, Hayashi K, Kaida I, Aki H, Yamamoto M. Permeation-enhancing effect of aloe-emodin anthrone on water-soluble and poorly permeable compounds in rat colonic mucosa. Biological and Pharmaceutical: Bulletin. 2002;25(12):1608-13.

8. Shin SC, Choi JS, Li X. Enhanced bioavailability of tamoxifen after oral administration of tamoxifen with quercetin in rats. International Journal of Pharmaceutics. 2006;313(1-2):144-9.

9. Vinson JA, Kharrat HA, Reoli L. Effect of Aloe vera preparations on the human bioavailability of vitamins C and E. Phytomedicine. 2005;12(10):760-5.

10. Nagy J, et al. Effect of grapefruit juice or cimetidine coadministration on albendazole bioavailability. American Journal of Tropical Medicine and Hygiene. 2002;66(3):260-3.

11. Capece BPS, Afonso SMS, Lazaro R, Harun M, Godoy C, Cristofol C. Effect of age and gender in the pharmacokinetics of albendazole and albendazole sulphoxide enantiomers in goats. Research in Veterinary Science. 2009;86(3):498-502.

12. Dudhatra GB, Mody SK, Awale MM, Patel HB, Modi CM, Kamani DR, et al. A comprehensive review on pharmacotherapeutics of herbal bioenhancers. The Scientific World Journal. 2012. Article ID 637953, 33.

13. Gupta KK. Bioavailability enhancers of herbal origin: An overview. Asian Pacific Journal of Tropical Biomedicine. 2013;3(4):253-66.

14. loannides C. Pharmacokinetic interactions between herbal remedies and medicinal drugs. Xenobiotica. 2002;32(6):451-78. 
PICTORIAL ABSTRACT

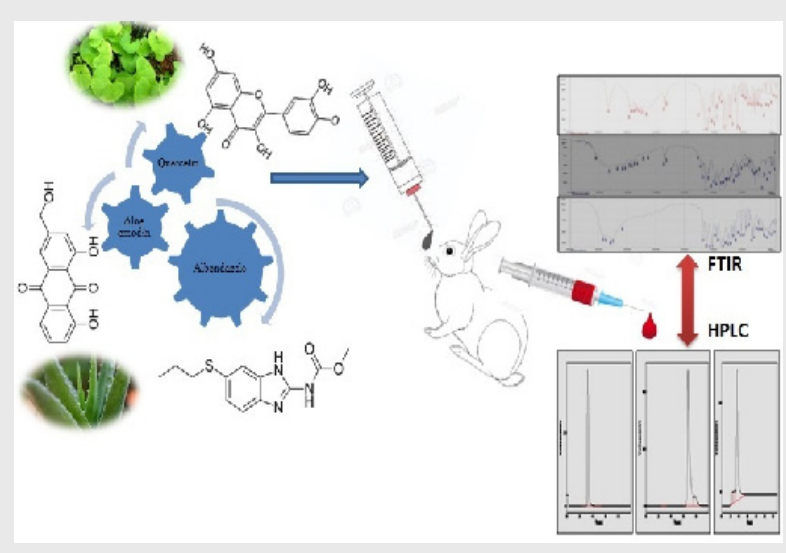

About Authors

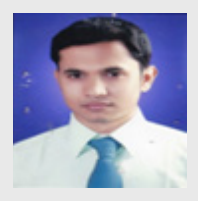

Mr. Harsh Verma is M. Pharm research scholar in Department of Pharmacology, Columbia Institute of Pharmacy Raipur, (C.G). He is working on the effect of phytoconstituents on the bioavailability of selected drugs through animal models.

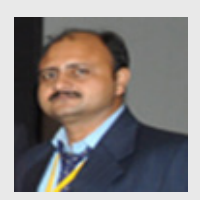

Prof. Ravindra Kumar Pandey is working as Professor, Department of Pharmacognosy at Columbia Institute of Pharmacy Raipur, (C.G). Author's area of interest includes conventional medicine system, standardization and chemical fingerprinting method development of Ayurvedic formulation and herbal formulation.

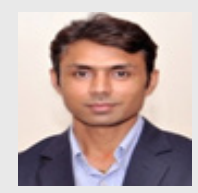

Prof. Shiv Shankar Shukla is working as Professor, Department of Pharmaceutical Analysis and Quality Assurance at Columbia Institute of Pharmacy. Author's area of interest includes instrumentation, standardization, validation and analysis of herbal and synthetic compounds.

\section{SUMMARY}

The drug Albendazole is poorly absorbed from the gastrointestinal tract due to its low aqueous solubility. Also, this hinders its oral bioavailability. The objective of the present work was to study the effect of two phytoconstituents (aloe emodin and quercetin) on the bioavailability of albendazole. HPLC chromatogram revealed that the retention time of albendazole was $3.2 \mathrm{~min}$ using acetonitrile and phosphate buffer as the solvent system. The study showed that albendazole was not detectable in 24 hrs plasma sample and values of AUC were found to be zero in all the selected concentration of phytoconstituents aloe emodin and quercetin. There was no change in tmax and the significant changes were observed in $\mathrm{C}_{\max }$ values. The $\mathrm{C}_{\max }$ was maximum i.e. $0.138 \mu \mathrm{g} / \mathrm{ml}$ when $20 \mathrm{mg} / \mathrm{kg}$ of quercetin was added in combination with Albendazole $28 \mathrm{mg} / \mathrm{kg}$. However, there was no significant change in these values when aloe emodin in concentration 10 $\mathrm{mg} / \mathrm{kg}$ and $20 \mathrm{mg} / \mathrm{kg}$ was added. The results prove that the bioavailability of Albendazole was increased with the presence of quercetin due to flavonoid content. And the phytoconstituent aloe emodin led to no significant increase in bioavailability of albendazole. Thus, the phyto constituents rich in flavonoids can be used to increase the bioavailability of poor soluble drugs. The bioavailability of albendazole pretreated with quercetin $(10 \mathrm{mg} / \mathrm{kg}$ and $20 \mathrm{mg} / \mathrm{kg})$ is increased $(p<0.05)$ significantly compared with the control (Albendazole $28 \mathrm{mg} / \mathrm{kg}$ ), but not by the aloe emodin. By pretreatment with aloe emodin $(10 \mathrm{mg} / \mathrm{kg}$ and $20 \mathrm{mg} / \mathrm{kg})$ there is no increase in bioavailability of albendazole. Previous studies reported that aloe emodin is an inhibitor of cytochrome enzymes in vitro but in the present study it was found there is no inhibitory effect on this enzyme system in vivo. Pretreatment with quercetin increases the bioavailability of albendazole significantly by the inhibition of cytochrome Cyp3a4 enzyme, which is mainly responsible for the metabolism of albendazole system and hence increases the bioavailability of albendazole.

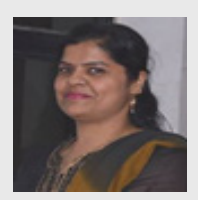

Dr. Bina Gidwani is working as Associate Professor, Department of Pharmaceutical Analysis and Quality Assurance at Columbia Institute of Pharmacy. Author's area of interest includes cyclodextrin complexation, nanotechnology, validation and analysis of herbal and synthetic drugs.

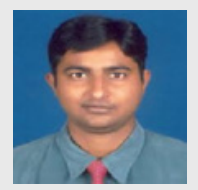

Dr. Amber Vyas is working as Assistant Professor, Department of Pharmaceutics, University Institute of Pharmacy, Pt. Ravishankar Shukla University, Raipur. Author's area of interest includes BCS drugs, cyclodextrin complexation, nanotechnology, solubilization techniques, chemotherapeutics drugs.

Cite this article: Verma H, Pandey RK, Shukla SS, Gidwani B, Vyas A. Investigation of Effect of Phytoconstituents Aloe Emodin and Quercetin on Bioavailability of Albendazole. Indian J of Pharmaceutical Education and Research. 2020;54(4):991-8. 